Journal of Systems Science and Information

Dec., 2015, Vol. 3, No. 6, pp. 513-524

DOI: $10.1515 /$ JSSI-2015-0513

\title{
Game Analysis in a Dual Channels System with Different Power Structures and Service Provision
}

\author{
Guoxing ZHANG \\ School of Management, Lanzhou University, Lanzhou 730000, China \\ E-mail: guoxingzh@lzu.edu.cn \\ Shuai FANG \\ School of Management, Lanzhou University, Lanzhou 730000, China \\ E-mail: mikefs@126.com \\ Kin Keung LAI \\ Department of Management Sciences, City University of Hong Kong, Hong Kong, China
}

\begin{abstract}
This paper studies a dual-channel supply chain in which a manufacturer sells products to a retailer as well as to customers who are sensitive to both channel price and the retail service. Three game models (Manufacturer Stackelberg, Retailer Stackelberg and Vertical Nash) are built according to members' different bargaining power in a dual channels system. The authors show that customers can receive lower channel price and higher retail service level when channel members have equal bargaining power, however, when the retailer occupies the market leadership, consumers always receive the least welfare because of the higher channel price and lower retail service. Interestingly, the retailer can take advantage of market leadership to make more profits, while the manufacturer is more willing to give up its power and act as a Stackelberg follower. Furthermore, Manufacturer Stackelberg and Vertical Nash is a strictly dominated strategy for the retailer and the manufacturer respectively.
\end{abstract}

Keywords dual-channel supply chain; price competition; service competition; Stackelberg/Nash game

\section{Introduction}

With the popularity of information technology, in addition to selling products through traditional retailers, many brand name manufacturers, including Dell, Nike, and Apple, have introduced online channels to sell products to customers directly. The manufacturer can use such a dual channels system to attract the customers with different needs, which can increase its profits and help it be more competitive. However, the presence of online direct channel can result in fiercer competition between the manufacturer and the retailer. In order to win more consumers, the retailer will provide the additional service. In the meanwhile, dual-channel supply chain members' different bargaining power can lead to different types of competition. A

Received November 13, 2014, accepted June 29, 2015

Supported by the National Natural Science Foundation of China (71103077) and Program for New Century Excellent Talents in University (NCET-13-0267) 
question therefore arises as to which type of game is the best for the manufacturer, the retailer and customers respectively in the dual-channel supply chain with channel price and the retail service competition? Our research is closely related to studies of dual-channel supply chain with price and service competition.

Indeed, there has been a large volume of research focused on channel selection and competition. Swaminathan and Tayur ${ }^{[1]}$ focused on supply chain issues with the prevalence of e-commerce, and discussed the contributions of relevant analytical research models. Chiang, Chhajed and Hess ${ }^{[2]}$ showed that direct channel can profit the manufacturer and may not always be detrimental to the retailer. Similarly, Cattani et al. ${ }^{[3]}$ analyzed pricing strategies for a manufacturer that might mitigate the channel conflict. Furthermore, Chiang and Monahan ${ }^{[4]}$ applied one-for-one inventory control policy, defined a cost structure in a dual-channel inventory model with stochastic demand for two consumer segments, and concluded that the dual-channel strategy outperforms the retail-only and direct-only strategies. Arya, Mittendorf and Sappington ${ }^{[5]}$ demonstrated that encroachment can lower the wholesale price, which can mitigate double marginalization problems and secure Pareto improvements. Furthermore, Arya, Mittendorf and Yoon ${ }^{[6]}$ demonstrated that a manufacturer can benefit from decentralized arrangements by imposing transfer prices above marginal cost. Hua, Wang and Cheng ${ }^{[7]}$ examined how delivery lead time influences the manufacturer's and retailer's pricing decisions. Liu and Zhang ${ }^{[8]}$ studied how entry into a direct distribution channel affects the manufacturer's and retailer's profits, and the retailer would embrace personalized pricing to deter the manufacturer from selling direct. Yan ${ }^{[9]}$ developed a game theory model which can help the multi-channel company determine the optimal pricing strategy. Park and $\mathrm{Keh}^{[10]}$ used game theory to look at the firm's marketing decision variables when hybrid channels exist.

Goal differences between channel members will lead to channel conflicts. Therefore, collaboration and coordination in the dual-channel supply chain has attracted much attention in the past few years. Kurata, Yao and Liu ${ }^{[1]}$ assessed supply chain coordination, and found that combining markup and markdown prices appropriately can coordinate supply chain and achieve a win-win outcome for each channel. Bernstein, Chen and Federgruen ${ }^{[12]}$ identified a condition under which perfect coordination of two-echelon supply chains with a single supplier and a network of retailers via simple schemes can be achieved. In order to adjust the manufacturerreseller relationship, Tsay and Agrawal ${ }^{[13]}$ examined some ways including changes in wholesale pricing and paying the reseller a commission. Chen, Zhang and Sun ${ }^{[14]}$ illustrated how the coordination schemes can coordinate the dual-channel supply chain and achieve a win-win outcome for each member. Shin and Benton ${ }^{[15]}$ investigated the impacts of environmental factors on the effectiveness of quantity discount-based inventory coordination policies between a buyer and a supplier. Cai ${ }^{[16]}$ proposed the contract coordination policy which is mutually beneficial for the supplier and the retailer in the contract-implementing Pareto zone. Boyaci ${ }^{[17]}$ stated that the presence of simultaneous vertical competition and horizontal competition can induce the channel inefficiencies, and designed an appealing two-part compensation-commission contract. Raju and Zhang ${ }^{[18]}$ developed a channel model with a dominant retailer, and showed that a manufacturer can select either quantity discounts or a menu of two-part tariffs as a channel coordination mechanism. 
In recent years, service has already become an important factor which affects consumers' channel choice. In order to maintain customer loyalty and attract new customers, both direct online channels and traditional retail channels try to provide additional service which can induce customers to make purchase decisions. First, some scholars study service provided in electronic channels, for example, Bernstein, Song and Zheng ${ }^{[19]}$ suggested a novel view that free riding may not produce a negative impact on supply chain performance, and examined how the free riding affects a manufacturer's channel structure decision. Lin and Mahmassani ${ }^{[20]}$ considered the logistical and distribution factors that influence the commercial viability of business operation models, and illustrated providing the high level of service delivered to customers leads to higher delivery costs. By considering time-dependent consumer demand, Hsu and $\mathrm{Li}^{[21]}$ formulated the nonlinear mathematical programming model to optimize a delivery service strategy, and suggested that discriminating service strategy is a better strategy. Secondly, some scholars conduct the research about service provided in traditional retail channels, for example, Dumrongsiri et al. ${ }^{[2]}$ built the dual channel supply chain in which consumers are sensitive to price and service qualities, and showed that an improvement in retailer's service quality may bring more profits to the manufacturer and both parties may benefit from a larger range of consumer service sensitivity in the dual channel through numerical analysis. Yao and $\mathrm{Liu}^{[23]}$ considered the price competition between e-tail and retail channel under the Bertrand and the Stackelberg settings, and examined how the retail services value and the marginal cost of retail services affect the equilibrium price. Similarly, Yan and Pei ${ }^{[24]}$ stated that the manufacturer's direct channel can result in the improved retail services, which could help the retailer obtain a higher sales volume and alleviate the channel conflict in a dual-channel competitive market. Mukhopadhyay, Yao and Yue ${ }^{[25]}$ presented the model where the manufacturer acts as the leader and the retailer adds value to the product at a cost, and considered the case of incomplete information the manufacturer may have about the retailer's value-adding cost. Thirdly, others focus on the manufacturer and the retailer providing service at the same time, for instance, Yrjola ${ }^{[26]}$ thought that on the basis of the traditional grocery shop, electronic grocery shopping operators offer service, and the supply chain should be redesigned to support EGS. In order to improve the service efficiency, Xiao, Dan and Zhang ${ }^{[27]}$ proposed the service-cooperation Stackelberg and Bertrand models in the dual-channel supply chain, and showed that the manufacturer's and the retailer's service cost have great effect on the channels' pricing decision.

As can be seen from the above literature review, most dual-channel supply chain literature focus on the competition and coordination between the channels in which consumers are price sensitive or service sensitive, however, they seldom consider that different power of supply chain members can result in different types of competition. It is a pity that they could not make a general evaluation concerning the impact of different types of game on competition equilibrium results. Therefore, this paper will attempt to build three game models of Manufacturer Stackelberg, Retailer Stackelberg, Vertical Nash, and evaluate which type of game is the best for the manufacturer, the retailer and customers respectively in the dual-channel supply chain when channels are competing in price and the retail service. 


\section{Problem Description and Model Building}

\subsection{Problem Description and Assumptions}

This paper considers a two-echelon dual channels system consisting of a manufacturer and a retailer, in which the manufacturer not only distributes products to customers through the retailer, but also sells products online. Direct channel and traditional retail channel sell similar products with a high substitutability, and consumers are sensitive to channel price and the retail service. Furthermore, when the manufacturer and retailer make strategic interaction, they have different power in decision making, which can result in different types of competition. For instance, the retailer who has more bargaining power than the manufacturer is viewed as the Stackelberg leader. The manufacturer who has more bargaining power than the retailer is regarded as the Stackelberg leader. The retailer and the manufacturer who have equal bargaining power will play Vertical Nash game.

Assumption 1 The manufacturer and retailer are risk-neutral decision makers.

Assumption 2 The manufacturer and retailer would make fully rational decisions under the complete information setting.

Assumption 3 The wholesale price is determined by the long-term contracts between the manufacturer and the retailer, and hence viewed as the exogenous variable independent of the model.

\subsection{Model Building}

We assume the demand functions for two channels are linear in price and service. The demand functions are as follows:

$$
\begin{aligned}
D_{t} & =a-p+b s_{t} \\
D_{d} & =a-p-b s_{t}
\end{aligned}
$$

The subscript $t$ and $d$ represent the traditional retail channel and direct channel respectively; $D_{t}$ and $D_{d}$ denote the traditional channel demand and direct channel demand respectively; $p$ is the channel price, and in order to ease the competition tension between two channels, the manufacturer is likely to keep the retail price in direct online channel consistent with that of traditional retail channel; $s_{t}$ represents the service provided by the retailer in a traditional retail channel; the parameter $b$ measures the responsiveness of the channel market demand to the retail service, and let $b>1$, which means that the market demand is more sensitive to the service than the price; $a$ is the intrinsic demand potential parameter and large enough, which reflects the market development level of this product.

Assuming that the relationship between service costs and service levels is nonlinear, we can set it with a quadratic form $C(s)=e s^{2} / 2$, in which $e$ is the service cost factor and measures the cost effectiveness of retail service. The quadratic form of the service cost function is used quite commonly in the previous literature ${ }^{[13,24]}$. It can not only simplify the reality problem, but also keep the nature of the model meaningful at the same time. This kind of quadratic form suggests diminishing returns on such expenditures. In details, the next dollar invested would bring lower service level than the last dollar. That is, providing the last unit of service becomes cheaper than the next unit of service. Without loss of generality, in order to simplify 
the exposition, we also assume the marginal production cost equal to 0 without affecting the basic results. Additionally, $w$ is the incremental wholesale price per unit.

\section{Manufacturer Stackelberg Game}

The game sequence of Manufacturer Stackelberg is as follows: Firstly, the manufacturer decides the channel price $p$ to maximize its profits $\pi_{m}$, and then according to the channel price set by the manufacturer, the retailer sets the service level $s_{t}$ in a traditional retail channel to maximize its own profits $\pi_{r}$. Next we are going to solve the optimal channel price and retail service through backwards induction method. Let the subscript $M^{*}$ denote equilibrium solutions under Manufacturer Stackelberg game.

The profit for the retailer is as follows:

$$
\pi_{r}=(p-w)\left(a-p+b s_{t}\right)-e s_{t}^{2} / 2
$$

The first-order condition characterizing equilibrium service is

$$
\frac{\partial \pi_{r}}{\partial s_{t}}=b(p-w)-e s_{t}=0
$$

Since $\frac{\partial^{2} \pi_{r}}{\partial s_{t}^{2}}=-e<0$, the retailer's profit function given price is strictly concave in service. Solving for $s_{t}$ from the above Eq. (4), we obtain the equilibrium service for the retailer:

$$
s_{t}=\frac{b(p-w)}{e}
$$

Similarly for the manufacturer, the profit is as follows:

$$
\pi_{m}=w\left(a-p+b s_{t}\right)+p\left(a-p-b s_{t}\right)
$$

Plug Equation (5) into Equation (6), and differentiate with respect to price and equate it to zero. We obtain the following formula:

$$
a-w+\frac{2 b^{2} w}{e}-\left(2+\frac{2 b^{2}}{e}\right) p=0
$$

Since $\frac{\partial^{2} \pi_{m}}{\partial p^{2}}=-\left(2+\frac{2 b^{2}}{e}\right)<0$, the manufacturer's profit function is strictly concave in price. Solving for $p$ from the above Equation (7), we obtain the equilibrium channel price:

$$
p^{M *}=\frac{(a-w) e+2 b^{2} w}{2\left(e+b^{2}\right)}
$$

Plug Equation (8) into Equation (5), and we obtain the equilibrium service:

$$
s_{t}^{M *}=b(a-3 w) / 2\left(b^{2}+e\right)
$$

The corresponding traditional retail and direct channel demand quantities at the equilibrium price and service are respectively:

$$
\begin{aligned}
& D_{t}^{M *}=\left(a e+e w+3 a b^{2}-5 b^{2} w\right) /\left(2 b^{2}+2 e\right) \\
& D_{d}^{M *}=(a+w) / 2
\end{aligned}
$$


The corresponding retailer's and manufacturer's profits at the equilibrium price and service are respectively:

$$
\begin{aligned}
& \pi_{r}^{M *}=e(a-3 w)\left(2 a e+2 e w+5 a b^{2}-7 b^{2} w\right) / 8\left(b^{2}+e\right)^{2} \\
& \pi_{m}^{M *}=\left(e a^{2}+8 a b^{2} w+2 e a w-8 b^{2} w^{2}+e w^{2}\right) / 4\left(b^{2}+e\right)
\end{aligned}
$$

\section{Retailer Stackelberg Game}

The game sequence of Retailer Stackelberg is as follows: Firstly, the retailer decides the service level $s_{t}$ in the traditional retail channel to maximize its own profits $\pi_{r}$, and then according to the service level set by the retailer, the manufacturer sets the channel price $p$ to maximize its profits $\pi_{m}$. Next we are going to solve the optimal channel price and retail service through backwards induction method. Let the subscript $R^{*}$ denote equilibrium solutions under Retailer Stackelberg game.

The profit function for the manufacturer is as follows:

$$
\pi_{m}=w\left(a-p+b s_{t}\right)+p\left(a-p-b s_{t}\right)
$$

The first-order condition characterizing equilibrium price is

$$
\frac{\partial \pi_{m}}{\partial p}=-2 p-b s_{t}+a-w=0
$$

Since $\frac{\partial^{2} \pi_{m}}{\partial p^{2}}=-2<0$, the manufacturer's profit function given service is strictly concave in price. Solving for $p$ from the above Equation (15), we obtain the equilibrium price for the manufacturer:

$$
p=\frac{-b s_{t}+a-w}{2}
$$

Similarly for the retailer, the profit function is as follows:

$$
\pi_{r}=(p-w)\left(a-p+b s_{t}\right)-e s_{t}^{2} / 2
$$

Plug Equation (16) into Equation (17), and differentiate with respect to service and equate it to zero. We obtain the following formula:

$$
\frac{-\left(2 e+3 b^{2}\right) s_{t}+a b-5 b w}{2}=0
$$

Since $\frac{\partial^{2} \pi_{r}}{\partial s_{t}^{2}}=-\left(2 e+3 b^{2}\right)<0$, the retailer's profit function is strictly concave in service. Solving for $s_{t}$ from the above Equation (18), we obtain the equilibrium service:

$$
s_{t}^{R *}=b(a-5 w) /\left(3 b^{2}+2 e\right)
$$

Plug Equation (19) into Equation (16), and we obtain the equilibrium price:

$$
p^{R *}=\left(a e-e w+a b^{2}+b^{2} w\right) /\left(3 b^{2}+2 e\right)
$$

The corresponding traditional retail and direct channel demand quantities at the equilibrium price and service are respectively:

$$
D_{t}^{R *}=\left(a e+e w+3 a b^{2}-6 b^{2} w\right) /\left(3 b^{2}+2 e\right)
$$




$$
D_{d}^{R *}=\left(a e+e w+a b^{2}+4 b^{2} w\right) /\left(3 b^{2}+2 e\right)
$$

The corresponding retailer's and manufacturer's profits at the equilibrium price and service are respectively:

$$
\begin{aligned}
\pi_{r}^{R *}= & \left(2 a^{2} b^{2}+e a^{2}-8 a b^{2} w-2 e a w+8 b^{2} w^{2}-3 e w^{2}\right) /\left(6 b^{2}+4 e\right) \\
\pi_{m}^{R *}= & \left(a^{2} b^{4}+2 a^{2} b^{2} e+a^{2} e^{2}+14 a b^{4} w+14 a b^{2} e w+2 a e^{2} w-14 b^{4} w^{2}-12 b^{2} e w^{2}+e^{2} w^{2}\right) \\
& /\left(3 b^{2}+2 e\right)^{2}
\end{aligned}
$$

\section{Vertical Nash Game}

If the manufacturer and the retailer in a dual-supply chain have the same power, they conduct a Vertical Nash game. The sequence of Vertical Nash game is: The manufacturer decides the channel price $p$ to maximize its own profits $\pi_{m}$; at the same time, the retailer decides the service $s_{t}$ to maximize its own profits $\pi_{r}$. Let the subscript $N^{*}$ denote equilibrium solutions under Vertical Nash game.

The profit function for the manufacturer is as follows:

$$
\pi_{m}=w\left(a-p+b s_{t}\right)+p\left(a-p-b s_{t}\right)
$$

The first-order condition characterizing equilibrium price is:

$$
\frac{\partial \pi_{m}}{\partial p}=-2 p-b s_{t}+a-w=0
$$

Since $\frac{\partial^{2} \pi_{m}}{\partial p^{2}}=-2<0$, the manufacturer's profit function given service is strictly concave in price, and the manufacturer can achieve maximum profits.

Similarly for the retailer, the profit function is as follows:

$$
\pi_{r}=(p-w)\left(a-p+b s_{t}\right)-e s_{t}^{2} / 2
$$

The first-order condition characterizing equilibrium service is

$$
\frac{\partial \pi_{r}}{\partial s_{t}}=b(p-w)-e s_{t}=0
$$

Since $\frac{\partial^{2} \pi_{r}}{\partial s_{t}^{2}}=-e<0$, the retailer's profit function is strictly concave in service, and the retailer can achieve maximum profits. Solving for $p$ and $s_{t}$ from Equation (26) and Equation (28), we obtain the equilibrium price and service:

$$
\begin{aligned}
& p^{N *}=\left(w b^{2}+a e-e w\right) /\left(b^{2}+2 e\right) \\
& s_{t}^{N *}=b(a-3 w) /\left(b^{2}+2 e\right)
\end{aligned}
$$

The corresponding traditional retail and direct channel demand quantities at the equilibrium price and service are respectively:

$$
\begin{aligned}
& D_{t}^{N *}=\left(a e+e w+2 a b^{2}-4 b^{2} w\right) /\left(b^{2}+2 e\right) \\
& D_{d}^{N *}=\left(2 w b^{2}+a e+e w\right) /\left(b^{2}+2 e\right)
\end{aligned}
$$


The corresponding retailer's and manufacturer's profits at the equilibrium price and service are respectively:

$$
\begin{aligned}
& \pi_{r}^{N *}=e(a-3 w)\left(2 a e+2 e w+3 a b^{2}-5 b^{2} w\right) / 2\left(b^{2}+2 e\right)^{2} \\
& \pi_{m}^{N *}=\left(a^{2} e^{2}+2 a b^{4} w+8 a b^{2} e w+2 a e^{2} w-2 b^{4} w^{2}-8 b^{2} e w^{2}+e^{2} w^{2}\right) /\left(b^{2}+2 e\right)^{2}
\end{aligned}
$$

\section{Equilibrium Analysis with Different Power Structures}

We have obtained equilibrium results in three competition scenarios in last section, and this part will contrast the dual-channel supply chain competition results above.

Proposition 1 In the dual-channel supply chain, the channel price in Retailer Stackelberg game is the highest, which is followed by Vertical Nash, and Manufacturer Stackelberg game leads to the minimum channel price.

Proof

$$
\begin{aligned}
& p^{R *}-p^{N *}=\left(b^{2}\left(2 e w+a b^{2}-2 b^{2} w\right)\right) /\left(3 b^{4}+8 b^{2} e+4 e^{2}\right)>0 \\
& p^{N *}-p^{M *}=\left(b^{2} e(a-3 w)\right) /\left(2\left(b^{4}+3 b^{2} e+2 e^{2}\right)\right)>0
\end{aligned}
$$

Therefore, we obtain $p^{R *}>p^{N *}>p^{M *}$.

Proposition 2 In the dual-channel supply chain, the service level in Vertical Nash is the highest, which is followed by Manufacturer Stackelberg, and Retailer Stackelberg game leads to the minimum service level.

Proof

$$
\begin{aligned}
& s_{t}^{N *}-s_{t}^{M *}=\left(b^{3}(a-3 w)\right) /\left(2\left(b^{2}+e\right)\left(b^{2}+2 e\right)\right)>0 \\
& s_{t}^{M *}-s_{t}^{R *}=\left(a b^{3}+b^{3} w+4 b e w\right) /\left(6 b^{4}+10 b^{2} e+4 e^{2}\right)>0
\end{aligned}
$$

Therefore, we obtain $s_{t}^{N *}>s_{t}^{M *}>s_{t}^{R *}$.

Propositions 1 and 2 have some implications below: when the retailer's power is stronger than the manufacturer's, the manufacturer has to improve the channel price, however, when the manufacturer occupies a larger market power, the manufacturer will lower the channel price to stimulate the market demand. Additionally, Vertical Nash game between the retailer and the manufacturer intensifies competition, and in order to maintain customer loyalty and attract new customers, the retailer can improve the service level in the traditional retail channel. When the retailer becomes the leader in Stackelberg game, considering the cost of the service level, the retailer might reduce the quality of service. From the perspective of customers, Retailer Stackelberg in the dual-channel supply chain is the most unfavorable situation, because at this time the channel price is the highest, but the customers receive the lowest level of service. By contrast, if the manufacturer and the retailer choose Vertical Nash game, customers can pay the moderate price level to enjoy the highest level of service, and therefore get more consumer welfare. Overall, when participants in the dual-channel competition are unable to act as the market leaders, customers can enjoy the lower channel price and enjoy more consumer welfare.

Proposition 3 In the dual-channel supply chain, the traditional retail channel demand in Vertical Nash is the largest, which is followed by Manufacturer Stackelberg, and Retailer Stackelberg game leads to the minimum retail channel demand. 
Proof

$$
\begin{aligned}
& D_{t}^{N *}-D_{t}^{M *}=\left(b^{2}(a-3 w)\left(b^{2}-e\right)\right) /\left(2\left(b^{2}+e\right)\left(b^{2}+2 e\right)\right)>0 \\
& D_{t}^{M *}-D_{t}^{R *}=\left(b^{2}\left(a e+3 e w+3 a b^{2}-3 b^{2} w\right)\right) /\left(2\left(3 b^{4}+5 b^{2} e+2 e^{2}\right)\right)>0
\end{aligned}
$$

Therefore, we obtain $D_{t}^{N *}>D_{t}^{M *}>D_{t}^{R *}$.

Proposition 3 indicates: Due to the model assumption that the dual-channel market is more sensitive to the retail service than the channel price, the level of the retail service plays an important role in the retailer's profits. Specifically, small changes in the traditional retail channel's service can cause sharp fluctuations in the traditional retail channel demand. When the retailer and the manufacturer play Vertical Nash game, the highest service level results in the maximum traditional retail channel demand, and when the retailer and the manufacturer choose Retailer Stackelberg game, the lowest service level in the traditional retail channel can lead to the lowest retail channel demand. From the perspective of the traditional retail channel market development, the retailer may give up the leading role in the game, and choose Vertical Nash game with the manufacturer, which can stimulate the traditional retail channel demand and be beneficial to the development of the traditional retail channel market.

Proposition 4 In the dual-channel supply chain, the direct channel demand in Manufacturer Stackelberg is the largest, which is followed by Retailer Stackelberg, and Vertical Nash leads to the minimum direct channel demand.

Proof

$$
\begin{aligned}
& D_{d}^{M *}-D_{d}^{R *}=\left(b^{2}(a-5 w)\right) /\left(2\left(3 b^{2}+2 e\right)\right)>0 \\
& D_{d}^{R *}-D_{d}^{N *}=\left(b^{2}\left(2 e w+a b^{2}-2 b^{2} w\right)\right) /\left(3 b^{4}+8 b^{2} e+4 e^{2}\right)>0
\end{aligned}
$$

Therefore, we obtain $D_{d}^{M *}>D_{d}^{R *}>D_{d}^{N *}$.

Proposition 4 indicates: In Vertical Nash game, the direct channel demand decreases to the minimum, for the increase in the retail service level makes some customers in the direct channel transfer to the traditional retail channel. As is stated in Propositions 1 and 2, the traditional retail channel's service level in Manufacturer Stackelberg game is higher than that in Retailer Stackelberg, and perhaps some customers in the direct channel are likely to choose the traditional retail channel, yet Manufacturer Stackelberg game prompts the manufacturer to reduce the price significantly, and furthermore the promoting impact of price reduction on the direct channel demand is greater than the inhibiting impact of the retail service improvement on the direct channel demand, and therefore it is seen that the direct channel demand in Manufacturer Stackelberg is greater than that in Retailer Stackelberg. From the perspective of the entire direct channel development, when the manufacturer enhances its own power and is willing to act as the leader, it might utilize its first-mover advantage to stimulate the direct channel demand, which is beneficial to promote the development of the direct channel.

Proposition 5 In the dual-channel supply chain, the retailer's profits in Retailer Stackelberg are the largest, which is followed by Vertical Nash, and Manufacturer Stackelberg leads to the minimum retailer's profits.

$$
\begin{aligned}
& \text { Proof } \\
& \pi_{r}^{R *}-\pi_{r}^{N *}=\left(b^{6} a(a-4 w)+4 a b^{4} e w\right) /\left(3 b^{6}+14 b^{4} e+20 b^{2} e^{2}+8 e^{3}\right)>0
\end{aligned}
$$




$$
\begin{aligned}
\pi_{r}^{N *}-\pi_{r}^{M *}= & \left(a b^{6} e(7 a-34 w)+a b^{4} e^{2}(10 a-36 w)+16 a b^{2} e^{3} w\right) /\left(8 b^{8}+48 b^{6} e+104 b^{4} e^{2}\right. \\
& \left.+96 b^{2} e^{3}+32 e^{4}\right)>0
\end{aligned}
$$

Therefore, we obtain $\pi_{r}^{R *}>\pi_{r}^{N *}>\pi_{r}^{M *}$.

Proposition 5 indicates: The retailer as a Stackelberg leader moves firstly, which can provide the retailer some advantages in human resources, natural resources, and organizational innovation. Therefore, the retailer can struggle to enhance its own power and make use of first-mover advantages to increase its profits. The retailer always prefers to choose Retailer Stackelberg game, but Manufacturer Stackelberg game is the retailer's strictly dominated strategy.

Proposition 6 In the dual-channel supply chain, the manufacturer's profits in Retailer Stackelberg are the largest, which is followed by Manufacturer Stackelberg, and Vertical Nash leads to the minimum manufacturer's profits.

\section{Proof}

$\pi_{m}^{R *}-\pi_{m}^{M *}=\left(a b^{6}(4 a-16 w)+a b^{4} e(3 a-2 w)+8 a b^{2} e^{2} w\right) /\left(36 b^{6}+84 b^{4} e+64 b^{2} e^{2}+16 e^{3}\right)>0$

$\pi_{m}^{M *}-\pi_{m}^{N *}=\left(a b^{4} e(a-6 w)\right) /\left(4 b^{6}+20 b^{4} e+32 b^{2} e^{2}+16 e^{3}\right)>0$

Therefore, we obtain $\pi_{m}^{R *}>\pi_{m}^{M *}>\pi_{m}^{N *}$.

Proposition 6 indicates: Compared to Stackelberg game strategy, Vertical Nash game strategy always damages the manufacturer's profits, that is to say, Vertical Nash game is the manufacturer's strictly dominated strategy. Generally speaking, if the game participant is lying in a dominant position competing with competitors (that is, the participant is the leader of Stackelberg game) in the dual-channel supply chain, the priority decisions can bring more benefits to Stackelberg game leader, but a surprising result shows that in order to make its situation better, a dominant manufacturer is not willing to use its power to game with competitors, and will choose to give up its power to act as a Stackelberg follower. As a decision follower, a manufacturer can get some second-mover advantages, for example, it can reduce the risks through the observation of the first-mover's experience in new market development and other marketing strategies.

\section{Conclusion}

Different from the previous literature, this paper considers power structure into a dual channels system which consists of a manufacturer and a retailer facing common end consumers who are sensitive to both the channel price and retail service. Additionally, we develop three possible game scenarios, namely, Manufacturer Stackelberg, Retailer Stackelberg and Vertical Nash respectively. Furthermore, we derive equilibrium expressions for channel price, retail service level, demand quantity and supply chain members' profits, and then contrast the results under three competition settings, which can give insights on which power structure is the most beneficial for the manufacturer, the retailer and customers.

The results show that consumers can get more benefits when supply chain members have equal power, which means that customers can receive higher retail service at the expense of lower price. A counterintuitive result shows that the retailer as a Stackelberg leader enjoys first-mover advantages in the decision making process, yet the manufacturer is more willing 
to act as a Stackelberg follower. Furthermore, Manufacturer Stackelberg and Vertical Nash is a strictly dominated strategy of the retailer and the manufacturer respectively. These above findings we get by applying a game theoretic concept into the dual-channel supply chain can fill the theoretical gap and serve as the foundation for the future empirical research.

While this paper provides the basis for future research on power structures in a dual channels system with service provision, there are limitations in our analysis. First, we assume a deterministic demand function that is linear in channel price and retail service variables in this paper, however, firms in supply chain are often facing uncertain demand, and hence further examination of the stochastic demand functions can gain more meaningful managerial insights. Second, the paper assumes the manufacturer and retailer are fully rational decision makers who possess complete information, but some information might be incomplete to them. Therefore, we can explore competition equilibriums under incomplete information setting.

\section{References}

[1] Swaminathan J M, Tayur S R. Models for supply chains in E-business. Management Science, 2003, 49(10): 1387-1406.

[2] Chiang W K, Chhajed D, Hess J D. Direct marketing, indirect profits: A strategic analysis of dual-channel supply-chain design. Management Science, 2003, 49(1): 1-20.

[3] Cattani K, Gilland W, Heese H S, et al. Boiling frogs: Pricing strategies for a manufacturer adding a direct channel that competes with the traditional channel. Production and Operations Management, 2006, 15(1): 40-56.

[4] Chiang W K, Monahan G E. Managing inventories in a two-echelon dual-channel supply chain. European Journal of Operational Research, 2005, 162(2): 325-341.

[5] Arya A, Mittendorf B, Sappington D E M. The bright side of supplier encroachment. Marketing Science, 2007, 26(5): 651-659.

[6] Arya A, Mittendorf B, Yoon D H. Friction in related-party trade when a rival is also a customer. Management Science, 2008, 54(11): 1850-1860.

[7] Hua G, Wang S, Cheng T C E. Price and lead time decisions in dual-channel supply chains. European Journal of Operational Research, 2010, 205(1): 113-126.

[8] Liu Y, Zhang Z J. Research note - The benefits of personalized pricing in a channel. Marketing Science, 2006, 25(1): 97-105.

[9] Yan R. Pricing strategy for companies with mixed online and traditional retailing distribution markets. Journal of Product \& Brand Management, 2008, 17(1): 48-56.

[10] Park S Y, Keh H T. Modelling hybrid distribution channels: A game-theoretic analysis. Journal of Retailing and Consumer Services, 2003, 10(3): 155-167.

[11] Kurata H, Yao D Q, Liu J J. Pricing policies under direct vs. indirect channel competition and national vs. store brand competition. European Journal of Operational Research, 2007, 180(1): 262-281.

[12] Bernstein F, Chen F, Federgruen A. Coordinating supply chains with simple pricing schemes: The role of vendor-managed inventories. Management Science, 2006, 52(10): 1483-1492.

[13] Tsay A A, Agrawal N. Channel conflict and coordination in the e-commerce age. Production and Operations Management, 2004, 13(1): 93-110.

[14] Chen J, Zhang H, Sun Y. Implementing coordination contracts in a manufacturer Stackelberg dual-channel supply chain. Omega, 2012, 40(5): 571-583.

[15] Shin H, Benton W C. Quantity discount-based inventory coordination: Effectiveness and critical environmental factors. Production and Operations Management, 2004, 13(1): 63-76.

[16] Cai G G. Channel selection and coordination in dual-channel supply chains. Journal of Retailing, 2010, 86(1): 22-36.

[17] Boyaci T. Competitive stocking and coordination in a multiple-channel distribution system. IIE Transactions, 2005, 37(5): 407-427. 
[18] Raju J, Zhang Z J. Channel coordination in the presence of a dominant retailer. Marketing Science, 2005, 24(2): 254-262.

[19] Bernstein F, Song J S, Zheng X. Free riding in a multi-channel supply chain. Naval Research Logistics, 2009, 56(8): 745-765.

[20] Lin I I, Mahmassani H S. Can online grocers deliver?: Some logistics considerations. Transportation Research Record: Journal of the Transportation Research Board, 2002, 1817(1): 17-24.

[21] Hsu C I, Li H C. Optimal delivery service strategy for internet shopping with time-dependent consumer demand. Transportation Research Part E: Logistics and Transportation Review, 2006, 42(6): 473-497.

[22] Dumrongsiri A, Fan M, Jain A, et al. A supply chain model with direct and retail channels. European Journal of Operational Research, 2008, 187(3): 691-718.

[23] Yao D Q, Liu J J. Competitive pricing of mixed retail and e-tail distribution channels. Omega, 2005, 33(3): 235-247.

[24] Yan R, Pei Z. Retail services and firm profit in a dual-channel market. Journal of Retailing and Consumer Services, 2009, 16(4): 306-314.

[25] Mukhopadhyay S K, Yao D Q, Yue X. Information sharing of value-adding retailer in a mixed channel hi-tech supply chain. Journal of Business Research, 2008, 61(9): 950-958.

[26] Yrjola H. Physical distribution considerations for electronic grocery shopping. International Journal of Physical Distribution \& Logistics Management, 2001, 31(10): 746-761.

[27] Xiao J, Dan B, Zhang X M. Service cooperation pricing strategy between manufacturers and retailers in dual-channel supply chain. Systems Engineering — Theory \& Practice, 2010, 30(12): 2203-2211. 